\title{
NAVAL CRAFT, WEAPON AND SENSOR SYSTEMS
}

\author{
Fr. Lürssen Werft
}

\begin{abstract}
The article provides an inside view on trends in technology of current and future naval construction programmes as seen by Lürssen, the German shipyard for naval vessels located in Bremen, Germany. The changing operational requirements recognised in many western European and overseas navies focus on a surface combatant such as a corvette-sized ship with advanced capabilities to meet the specific demands for littoral warfare operations. Based on these new requirements the article outlines technologies in current and future designs for Corvette- and Frigatesized ships. It includes different types of platforms together with their specific benefits and capabilities for the intended employment in littoral warfare. In addition, measures to reduce the ship's signatures for enhanced survivability are broadly discussed. With respect to adequate sea-keeping, manoeuvrability, speed and endurance (properties) in the littoral environment, the article also expands on the development and characteristics of new propulsion systems emphasising the overall need for a high degree of automation in all system components. The discussion on modern combat system technology once again underlines the need for a modular and flexible system design with open system architecture. The highest possible level of system automation reducing the number of personnel in the CIC and ensuring immediate reaction in a threat scenario is a further topic. Full integration of all sensors and weapons coupled with proven operational software is the essential technical requirement in this context. Finally, the article comments on some economical aspects of current building philosophies touching thereby on possibilities for crew reduction, costs reduction, potential capabilities for midlife refit, and growth potential.
\end{abstract}

The overall issue of "Transforming the Bulgarian Navy" is aimed at a permanent adaptation of Bulgarian Naval Forces to achieve high performance standards and combat effectiveness to meet the requirements of maritime warfare in the $21^{\text {st }}$ century including those of interoperability and joint forces operations. This article on "Technologies for Advanced Naval Capabilities" has been developed from a leading modern shipyard's point of view, based on some essential convictions:

- A glance at trends of technologies in current and future naval construction programmes will show that evolution in modern shipbuilding has not come to an end and is continuing; 
- Changing operational requirements for surface combatants due to the current global threat perception are demanding that these new technologies are integrated into combat ships of the future;

- The most important aspect driving future shipbuilding programmes worldwide will be the overall requirement for the vessels' littoral warfare capability and effectiveness to counter asymmetric attacks;

- Procurement programmes will increasingly be ruled by nations' restricted defence budgets.

\section{Background of LÜRSSEN}

Fr. Lürssen Werft (LÜRSSEN) in Bremen, Germany, has a remarkable record of success in building advanced and high quality innovative vessels for use in the German Navy and navies of the world. LÜRSSEN has gained a worldwide reputation particularly from construction programmes of fast attack craft (FAC), helicopter corvettes, fleet support ships and mine countermeasure (MCM) vessels.

LÜRSSEN's overall high-tech profile is marked by a number of "world's firsts" technical innovations, such as for example:

- The development of the semi-displacement hull, now forming the basis for all modern fast patrol boat (FPB) and FAC designs;

- Construction of the first helicopter corvette under 1000 tons with flight deck and hangar;

- Installation and integration of the first CIWS GOALKEEPER on a small corvette;

- Integration of the first Point Defence Missile System (PDMS), type RAM, on FPBs and other surface combatants;

- Development of the first fully operational remote controlled minesweeping system.

Over the last decades LÜRSSEN has increased the range of products even to tenders and fleet support vessels such as the German Navy ship BERLIN, of the class of more than $170 \mathrm{~m}$ length and 20,000 $\mathrm{t}$ displacement. LÜRSSEN is also fully involved in the production of the German frigate, type 124.

Currently, LÜRSSEN in partnership with two other German shipyards designs and builds the German Navy corvette, type 130 (see Figure 1). 


\section{New Operational Requirements for Future Naval Vessels}

Today naval shipbuilding in Germany and in Europe is particularly challenged by new operational requirements of many regional nations bordering the sea. The need for rapid transformation of proven technologies and the development of more advanced technologies for new operational capabilities is driven by the magic term "Littoral Warfare Operations."

\section{Historical Review}

Until the end of the "Cold War" in the early nineties of the last century military planning, concept and operations were centred on national defence and on securing the area of NATO nations' interest and responsibility.

German Naval Forces were therefore at that time primarily tasked with homeland defence and safeguarding the coastal waters and transit routes in the Baltic and the North Sea. To achieve the overall objective of homeland defence and national security the German Fleet was mainly composed of smaller vessels such as Fast Patrol Boats (FPB), mine warfare vessels, tenders and submarines; all types being specifically designed for operations in the coastal waters. The destroyer/frigate components of the German Fleet, however, were assigned blue water tasks of escorting and protecting NATO convoys and Task Groups on their way from the Atlantic to national waters and ports.

\section{Littoral Warfare - the New Area of Operation}

In accordance with the development of the global political situation Germany is currently dealing with concepts and measures of a new defence strategy covering conflict prevention, crisis reaction and management as well as collective defence within a multi-national framework. Predominantly maritime forces will carry out these types of operations in the so called littoral sea areas, at long distances from own homeports and support bases.

Littoral areas comprise both the sea area from the open sea towards the coast and the strip of land ashore where own ground forces may have to operate, supported by naval assets. Operations in the littorals are by nature "Joint Operations," involving all three services (army, air, navy) under one common command. In most cases operations in the littorals will be carried out on a multi-national basis in multi-nation Task Groups or Task Force.

\section{Advanced Capabilities for Future Naval Vessels}

Future naval vessel designs intended to be employed in the littorals and in a multi-national formation require specific capabilities in order to cope with new specific tasks: 
- Carry out tactical surveillance, reconnaissance and patrol in order to establish a picture of the tactical situation,

- Control of defined sea areas, transit routes and commercial shipping,

- Destroy, neutralise or deter hostile threats ashore in support of own ground forces,

- Destroy, neutralise or deter hostile surface forces afloat,

- Ensure self-protection and/or unit protection against air, subsurface and surface threats,

- Counter asymmetric (terrorist) attacks,

- Protect (cover) own forces' operations, for example own MCM operations or amphibious landing operations,

- Provide service support to and from own forces ashore.

With these naval capabilities, the operational requirements for operations in a high threat environment including conflict prevention, embargo control, crisis management and defence against terrorist attacks are ideally fulfilled by surface vessels of corvette-type ships.

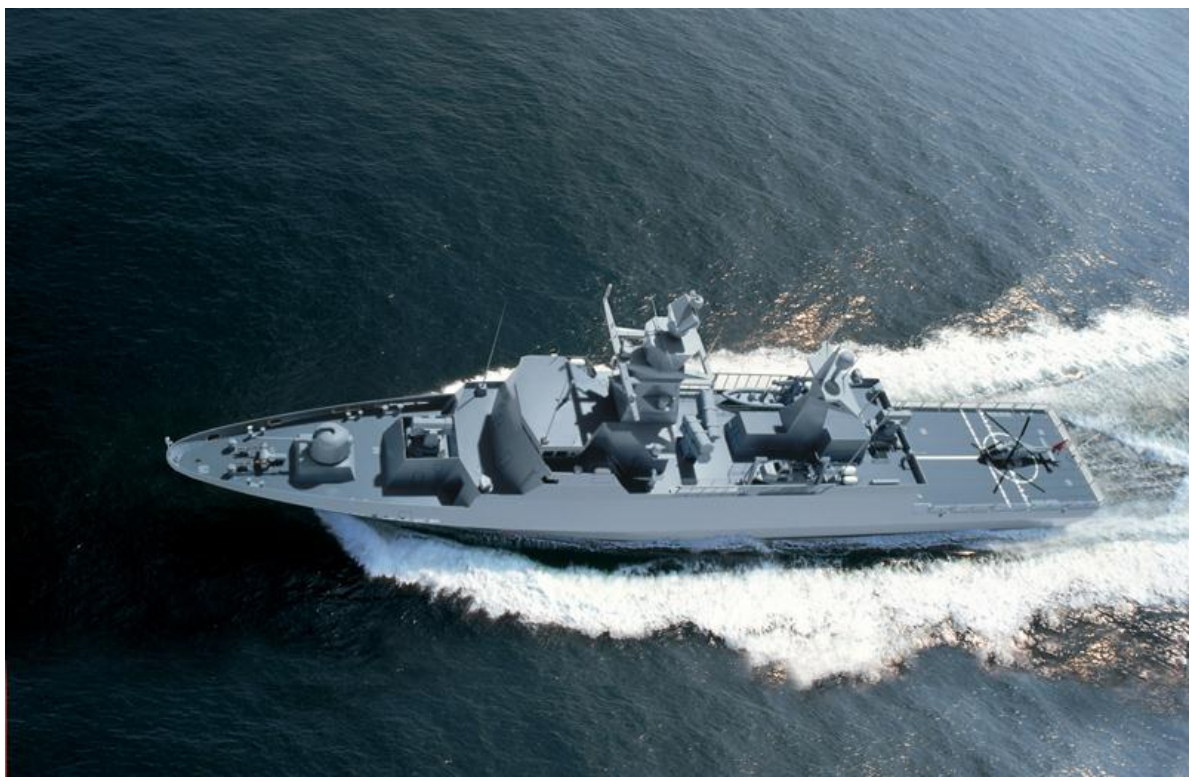

Figure 1: German Corvette, Type 130, for Littoral Warfare. 


\section{Example of a Corvette for Littoral Operations}

One example of a current corvette design specifically developed to meet the challenging requirements arising from littoral warfare is the German corvette, type 130.

Initially planned as replacement of German FPBs, the design was adapted to the new and wider scope of missions for littoral warfare. Due to its larger size, the corvette has a significantly longer endurance, an enhanced sea-keeping capability and increased sustainability. At an early stage of a crisis the corvette can relocate to the theatre of operation over long distance. With the K 130 the German Navy is able to operate - coming from the open sea-in coastal waters or close to the coastline either together with or in support to other navies. With its capability to engage targets ashore the corvette is particularly able to support own and allied ground forces operating ashore. This is possible by the land attack capability of the long range surfaceto-surface missile installed on the vessel. Thus the K 130 corvette provides for sustained operations in littoral warfare with a high level of survivability. She is also capable of long range open and covert surveillance through the employment of naval drones and ensures sea-based engagements of surface targets at sea and ashore.

\section{Technologies and Trends in Corvette Design}

\section{Platform, Design}

\section{Tasks and Size}

Innovative corvette design is determined by the missions of the user navy and the required capabilities which have been drafted above as well as by the technical progress in naval engineering and related industries.

Technological progress of the naval industry may influence survivability, reliability, environmental protection and total cost. The total cost of a naval vessel comprises costs for production and lifecycle/maintenance cost.

The production costs of a vessel are directly influenced by the size and design of the vessel. The design, therefore, should be tailored to the specific needs and should not be larger than necessary. Varying tasks are accomplished by modular and exchangeable equipment. Thus a vessel for littoral warfare with a minimised crew of 60 to 80 people personnel may be as small as 70 to 100 metres.

With the 60 metres + corvette class delivered to various navies, LÜRSSEN has proven that a powerful combat vessel does not need to be huge. An effective combination of missiles and guns together with a flight deck and a high performance combat management system can be integrated onto a ship of under 100 metres in length.

With respect to lifecycle cost, costs for personnel, maintenance, repair, and fuel accumulated over the life of the vessel, costs can easily exceed the procurement cost. 


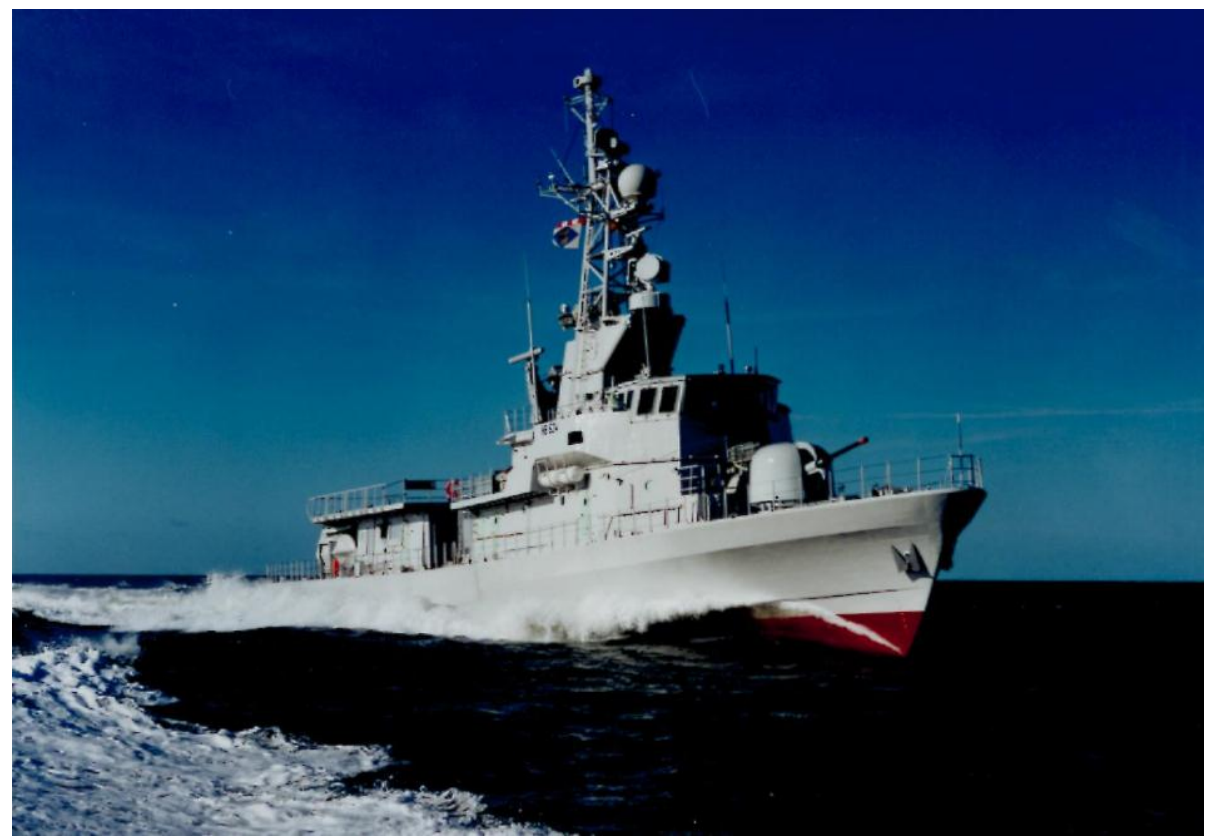

Figure 2: LÜRSSEN Corvette CM 65 - A Compact Vessel with High Combat Power.

Therefore the vessel's systems should be state-of-the-art equipment prepared for the future with low emissions, low maintenance requirements, a high level of automation and replaceability, and low consumption of consumables.

Future naval vessels can be operated with a crew reduced by $50 \%$ or more compared to the vessels of the late $20^{\text {th }}$ century. This crew reduction is possible due to the high degree of automation, and the smart crew management that considers all the capabilities and skills of each individual crew member. As a result, the next generation of corvettes and frigate-sized vessels can be operated by a crew of 60 to 80 persons.

\section{Hull Forms and Hull Lines}

Nowadays the monohull is the standard hull form for naval vessels. Alternative hull forms which in recent times have been discussed and evaluated are:

- The SWATH (small waterplane area twin hull) concept,

- The trimaran,

- Types of catamarans,

- Types of air cushion vehicles (ACV), and

- $\quad$ The wave piercer mono-hull. 
All these alternative hull forms provide certain advantages under specific operational conditions. In general, multi-hull vessels have the advantage of the very high initial stability resulting in small heel angles but high accelerations. However, they have a limit for seaworthiness which is determined by the distance of the individual hulls and the height of the transverse connections between these hulls.

A naval vessel designed for worldwide operation should not suffer such operational limits. Naval vessels have to survive under the most unfavourable sea conditions. Regarding modern Combat Direction Systems the ship motions as roll and pitch are less of a problem than high transverse accelerations. As a general approach the monohull, therefore, can be considered as the hull form of the past and of the future.

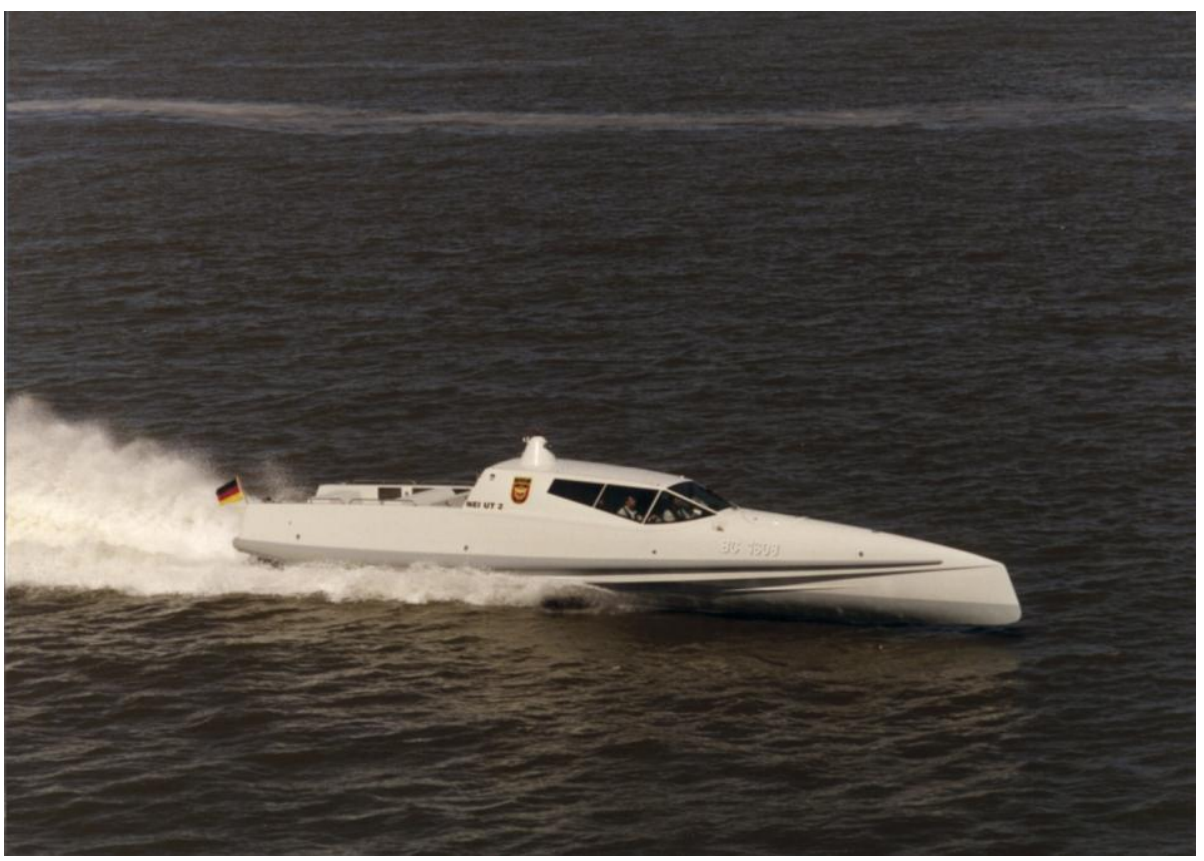

Figure 3: LÜRSSEN VSV 15 (design by Paragon Mann) - An Alternative Hull Form for Small Interceptor.

The hull lines are the source of resistance, engine power, fuel consumption and seakeeping. Nowadays optimisation of hull lines is done by means of computer fluid dynamics (CFD) in the computer long before the first tank test is performed. New developments for monohulls are:

- The parallel or even broadened aft body of the vessel compared to the slim yacht stern in the past, 
- The slender bulbous bow for resistance and slamming reduction, and

- Flexible trim wedges or interceptors at the transom.

Wave piercing hull forms have proven to be successful for small interceptors, as for example in the LÜRSSEN built VSV 15 (Figure 3).

Wave piercer investigations for vessels of corvette and frigate size, however, revealed strong interference by green seas much more often washing over deck than with conventional bow shapes reducing the vessel's speed and causing big longitudinal accelerations.

\section{Materials}

Steel is the most often applied material for ocean going vessels including naval vessels. Steel is strong, elastic, homogenous, easy to work with and relatively cheap. However, some of the disadvantages are corrosion and heavy weight.

Corrosion can be controlled by either passive measures (zinc anodes) or active cathodic protection systems and, naturally, by careful coating. Non-corrosive materials used for shipbuilding comprise aluminium which is used for smaller patrol boats, reinforced plastics, either CRP (carbon fibre) or GRP (glass fibre) and austenitic steel. Austenitic steel, used for submarines and by LÜRSSEN for mine counter measure vessels, is a perfect material for any type of vessel. However, the price of the material dictates that it will be used only for special ships with requirements for non-magnetic characteristics.

The most common types of steel are shipbuilding steel grade GL-A (Germanischer Lloyd) and higher tensile steel GL-D 36. For the ships of corvette size such material allows for minimum scantlings and modular construction.

Steel is perfectly suited for the application of laser cutting and welding machines providing a high level of accuracy and quality. Steel sections and modules can be constructed at different locations based on the same CAD model and can be easily matched together. This is important since future naval projects more and more require the cooperation between different shipyards during design and production.

\section{Modular Design}

Future corvette components and equipment need to be modular and exchangeable. One example for modular mission is the container concept which is in use with the German Navy's support vessels type 404 (Elbe class) and type 702 (Berlin class, EGV), both constructed by LÜRSSEN. The containers house workshops, stores and even hospitals. In the future, dedicated standard containers may accommodate mine warfare equipment or unmanned aerial vehicles together with their launching catapult. 
Also equipment installed on the vessel may need to be substituted by more modern equipment. Plug-and-play solutions as known from computer science are demanded in the future. They cover weapons, electronics, machinery and even accommodation in modular solutions.

\section{Survivability of Future Naval Vessels}

Survivability is based on protection and redundancy.

Protection includes stability, seaworthiness, armour protection and NBC (nuclear, biological, chemical) protection. Stability and seaworthiness are mainly influenced by the hull lines. Armour protection with modern composite structures using kevlar and ceramic tiles is a new technology, especially required in an asymmetric threat.

Splinter protection will protect all vital areas from small calibre ammunition and splintering. It can be planned for during design or can also be retrofitted on the vessel during service.

NBC protection today is a standard technology. Modern systems are based on a continuous overpressure maintained constantly. The ship is entered via double door air locks. NBC filters are integrated in the ventilation systems and provide air for each damage control (DC) zone individually. New technologies are applied to reduce the size and weight of equipment.

Redundancy is required as a backup solution since a failure of a system cannot be totally avoided and no system can be protected perfectly against all threats and all the time. This is of increased importance when accepting for naval vessels a reduced crew and hence damage control teams of a limited capacity. It is of a high importance then to identify vital equipment, which is to be provided at least twice on board at a maximum spacing in between. Vital and, consequently, redundant systems are:

- Propulsion trains,

- Rudders,

- Nuclear, biological, and chemical protection systems,

- Fire-fighting systems,

- Damage control systems, and

- Diesel generators and electrical switchboards.

Most of these systems are distributed over different DC zones. Depending on the ship's size there are two to four different zones independent of each other.

Until now only a few warship designs provide redundant propulsion and manoeuvring systems in different DC zones. In the future there will be a growing demand for the redundancy of the propulsion systems which can be satisfied by the fully electrical 
approach in combination with retractable thrusters or propulsors fitted at different locations to the hull.

\section{Technologies for Future Propulsion Systems}

\section{Aim/Objectives}

\section{General}

Modern surface combat craft with variable mission profile requires high capabilities and performance for the propulsion and power generating systems. Main topics are:

- Economic operation,

- Low emission,

- Low noise levels,

- High redundancy,

- Reduced signature,

- High degree of automation, and

- Design flexibility.

The prime movers of propulsion and power generating systems of today's combat craft are diesel engines or gas turbines driving either controllable or fixed pitch propellers or conventional water jets.

The potential for further improvement of the conventional propulsion and power generating systems is limited; however, components of the propulsion system give chances for improvement. For future systems specific equipment may be considered:

- Fuel cells (for power generation) and

- Pods (as propulsors).

\section{All Electric Ship}

The integration of these two components requires an All Electric Ship design which offers the advantage of a decentralised arrangement of both energy generating components as well as of propulsors.

The electric drive systems are more efficient than the conventional mechanical drive ones due to the eliminated need for reduction gears. In addition to supplying propulsion power to the vessel, the integrated power generating system manages and supplies power for all other systems, such as for example lighting, computer systems and combat systems.

Within the All Electric Ship the consideration of High Temperature Superconducting electric systems (HTS) technology for generators, motors and cabling may offer ad- 
ditional advantages in size, weight and efficiency of equipment.

\section{Podded Drives}

The All Electric Ship design permits a totally open ship in terms of arrangement, allowing even for podded propulsors.

The advantages of electrically driven pods, stated briefly, are:

- Excellent manoeuvrability,

- Low noise level,

- Excellent low speed capability, and

- Reduced installation time and costs.

In combination with fixed pitch propellers or water jets as main propulsors for high speed, podded drives are highly qualified as propulsors for cruising speeds.

Disadvantages of the podded drives are mainly the limited availability of propulsion power, the high weight and finally the high price up to now.

\section{Fuel Cells}

Now the fuel cell technology has not been developed to a degree that it can be integrated into a surface vessel as a continuous energy source for propulsion. However, for applications where cost, space, and weight are not decisive factors, fuel cells may be considered as energy source for restricted power generation offering a reduction of pollution emissions, noise, and vibrations. Also, a full independence from shore connections may be achieved.

\section{Final Considerations for Future Propulsion Systems}

The conventional propulsion and power generating systems are well proven and fulfil most of the requirements for a modern combat craft. The initial and through-life costs are reasonable. Therefore, these systems will also play an important role for future combat crafts.

The All Electric Ship with a distributed propulsion and power generating system may be an attractive solution for future combat craft from corvette to frigate size.

The main advantages of the All Electric Ship are:

- Operating flexibility, safety, reliability,

- Improved efficiency at low speeds and when manoeuvring,

- Increased manoeuvrability,

- Reduced maintenance, and 
- Optimisation of ship's layout.

\section{Signature Management}

The first waves of "super stealth" ships named Sea Shadow (USA), YS 2000 (Sweden) and Sea Wraith (UK) ebbed away. These ships proved "how much stealth" was possible and the question what are these ships good for was raised.

Today and tomorrow stealth, which means signature management, will play a major part in all naval vessel designs but there should not be any restrictions in safety, manoeuvrability and of course in combat strength.

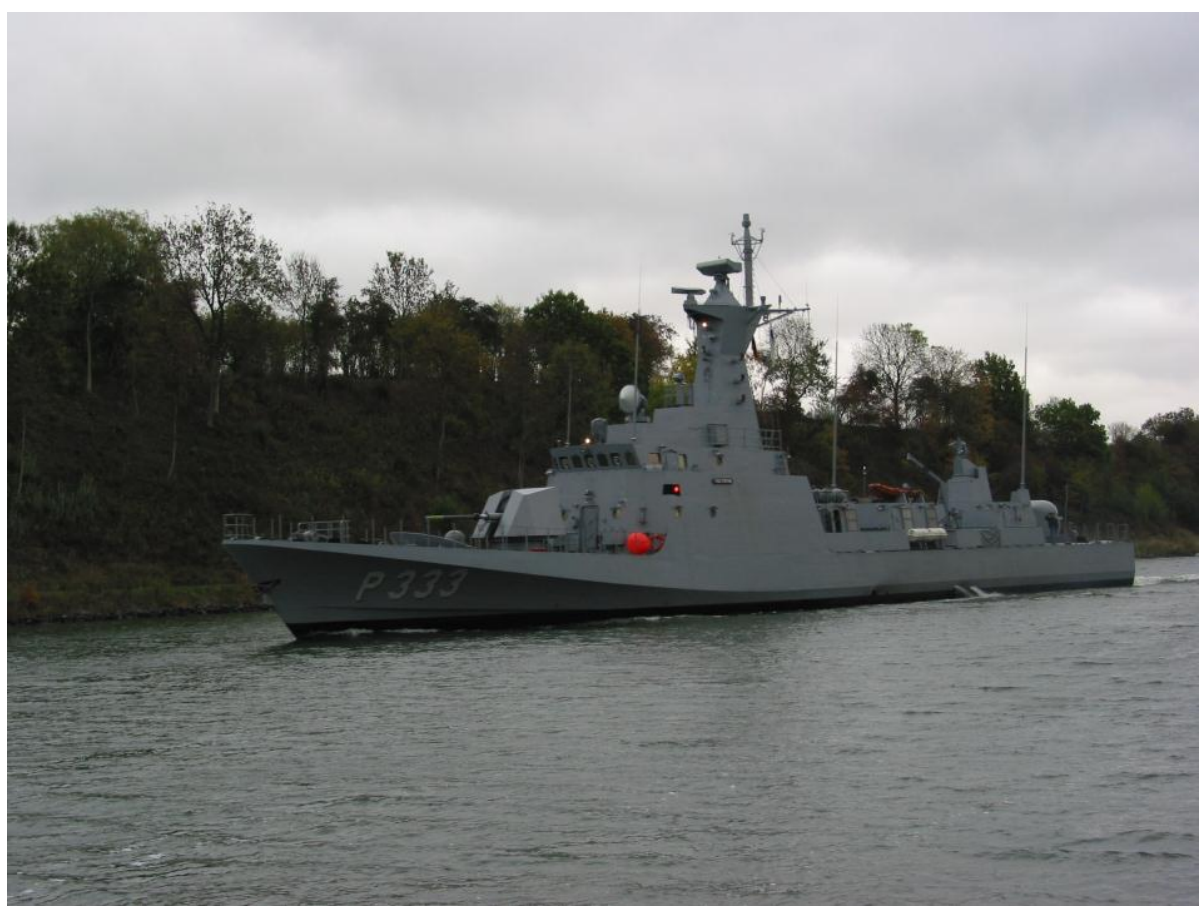

Figure 4: Turkish Navy Fast Attack Craft - Proven Stealth without Loss of Operational Performance.

Thus the designer is asked for new and innovative solutions. Such innovative solutions may be hidden and are visible only for radar, infrared seeker or sonar.

For surface vessels the most important signatures are the optical signature, radar signature, infra-red signature and acoustic signature. These signatures are detected by 
sensors of other vessels, aircraft, missiles and submarines. The reduction of these signatures shall

- Reduce the distance of possible detection with the aim to detect the other vessels/aircraft before they detect the own vessel,

- Confuse the enemy about the real size, shape, type and characteristic of the own vessel, and

- Support an effective engagement of decoy and chaff ammunition to divert missiles.

Modern seekers of guided missiles, however, have infrared sensors of such a high resolution that detection of the vessel may only be delayed. It is, however, not realistic that the reduction of signatures at any time will make the vessel "invisible."

\section{Radar Cross Section (RCS)}

The radar signature is measured as radar cross section (RCS) in $\mathrm{dB}\left(\mathrm{m}^{2}\right)$. Stealth shaping by flat inclined surfaces, tumblehome and avoidance of corner reflectors led to a remarkable reduction of RCS of present ship's structure. Nowadays the RCS of the deck equipment is more intense than that of the ship herself. The reduction of the RCS contributed by equipment can be reduced by:

- Selection of stealth equipment: e.g., guns equipped with stealth shaped cupolas, railing stanchions made from rectangular sections, yards and other equipment made from radar transparent materials,

- Covering of deck equipment by bulwarks, radar reflecting metallic meshes, and radar reflecting covers,

- Installation of equipment below deck: e. g. use of vertical missile launchers,

- Coating/covering of equipment with radar absorbing materials (RAM) and paints,

- Removable equipment, removed under battle conditions, and

- Wires in window panes (radar reflecting).

\section{Infrared Signature}

The infrared signature is created by the heat sources of the vessel, in particular the engine exhausts, and by the effects of sun radiation. Reflection of the sun and solar heating are both significant signatures but each in a different frequency range. The sun effects may be suppressed by:

- Water sprinklers distributed all over the metallic surfaces to cool down the surfaces, and 
- Special paints and coatings which diffuse the bright sunlight but which also do not heat up.

A good trade-off may be the use of the NBC sprinkler system for cooling down the metallic surfaces. More sophisticated IR reduction sprinkler systems are presently being developed.

A typical hot spot of any vessel is the funnel with the heat exhausts. Since decades it is for LÜRSSEN state-of-the-art technology to provide vessels with underwater exhausts, where the diesel exhaust/gas is merged with the water and becomes difficult to detect.

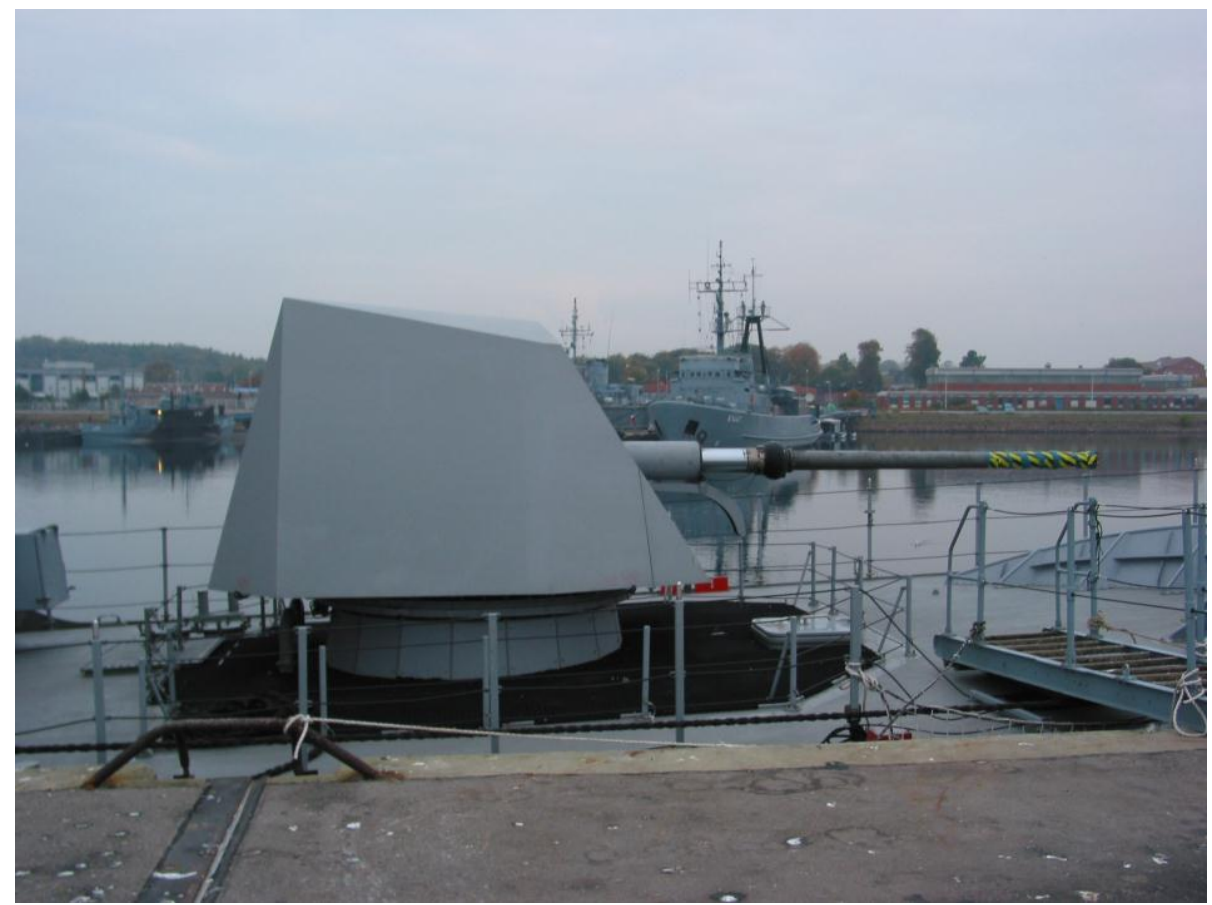

Figure 5: New $76 \mathrm{~mm}$ Gun with Stealth Cupola integrated by LÜRSSEN.

\section{Acoustic Signature}

A low acoustic signature protects the vessel from detection by submarines, torpedoes and mines. The key technologies used for years now are:

- Cavitation free propellers, highly skewed with controllable pitch and working with low revolutions, 
- Double elastic main engine foundations, e.g. for MCMVs,

- Elastic mounting of all rotating machinery, and

- Noise capsules for diesel generator sets and other machinery.

New technologies are closely connected to advanced propulsion systems and new energy concepts as listed above. The All Electric Ship will allow for an installation of diesel generator sets where useful, the main engines are not connected to the propellers any longer. These diesel generator sets can be closed-in and elastically mounted.

Podded propeller systems work in an undisturbed wake since there are no shaft brackets. Therefore they run much quieter than propellers arranged conventionally on a horizontal shaft.

Fully submersed water jet units are expected to have a very low acoustic signature. It has to be proven in the future.

\section{Combat Systems Technologies}

CS Design Technology

Operational missions in littoral sea areas call for an optimised state-of-the-art combat

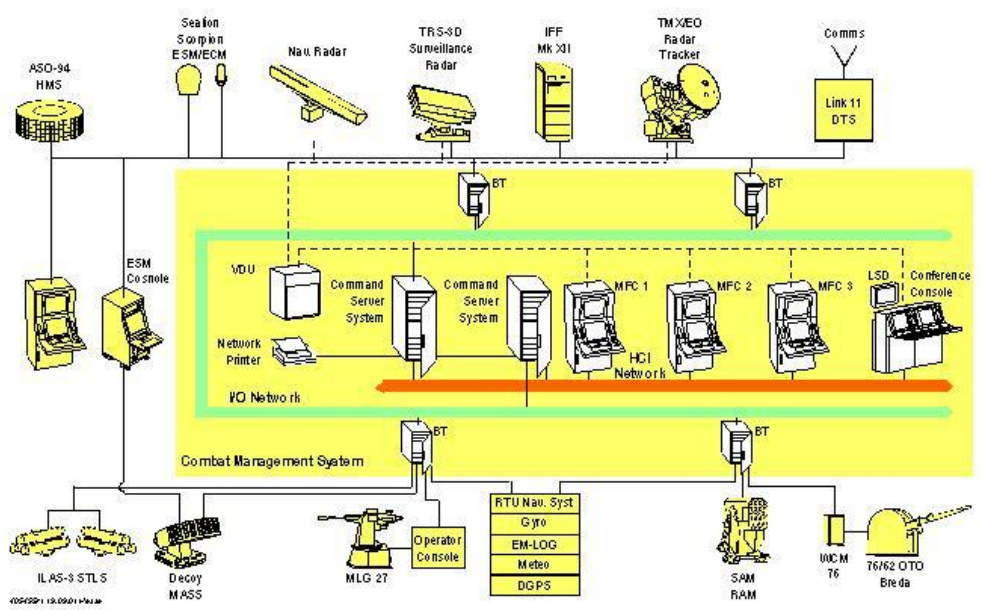

Figure 6: Advanced Combat System (CS) - Example. 
system (CS) to be installed on the littoral warfare ships. This is an urgent requirement in order to ensure superior reaction times, to cope with the increased number of threats in the littoral environment, and to provide the required support to ground forces ashore.

A modern combat system consists of the CS infrastructure (consoles, displays, interface computers and system software) and the operational software derived from the navy's operational tactics and procedures. Advanced CS technology is characterised by a very high degree of automation.

State-of-the-art technology applied to modern combat systems comprises a modular and flexible design in a distributed multi-node open architecture configuration.

The weapons and sensors are controlled by the CS through a number of multi-function consoles (MFC). The CS automatically processes the data from external sources, i.e. tactical data link, and from own sensors; prepares and displays a situation map. The main threat, i.e. air and surface threat, is automatically calculated and indicated to the operator. In modern CS, sensors and weapons are linked to functional chains for automatic target engagements.

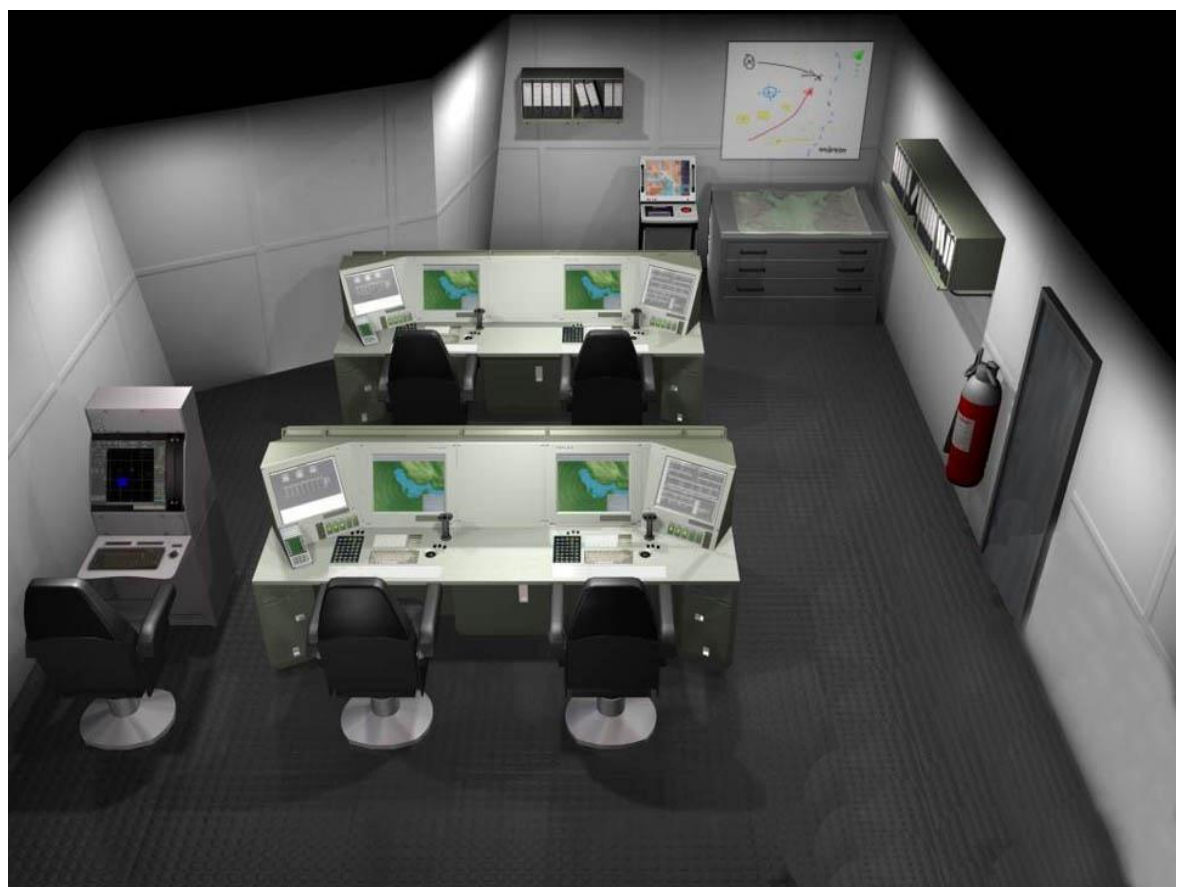

Figure 7: Example of Modern OPS Room Design 
Operational tasks of OPS room personnel are executed via the MFCs which are serviced by a distributed multi-node processing over redundant computers, data bus including a video system. The MFCs allow for simultaneous display of tactical data as layover to sea and chart information of the respective (littoral) area of operations.

The modular open architecture of modern CS is composed of logically structured software clusters or modules such as the planning, the threat evaluation and weapon assignment (TEWA), control, training and simulation clusters (Figure 8).

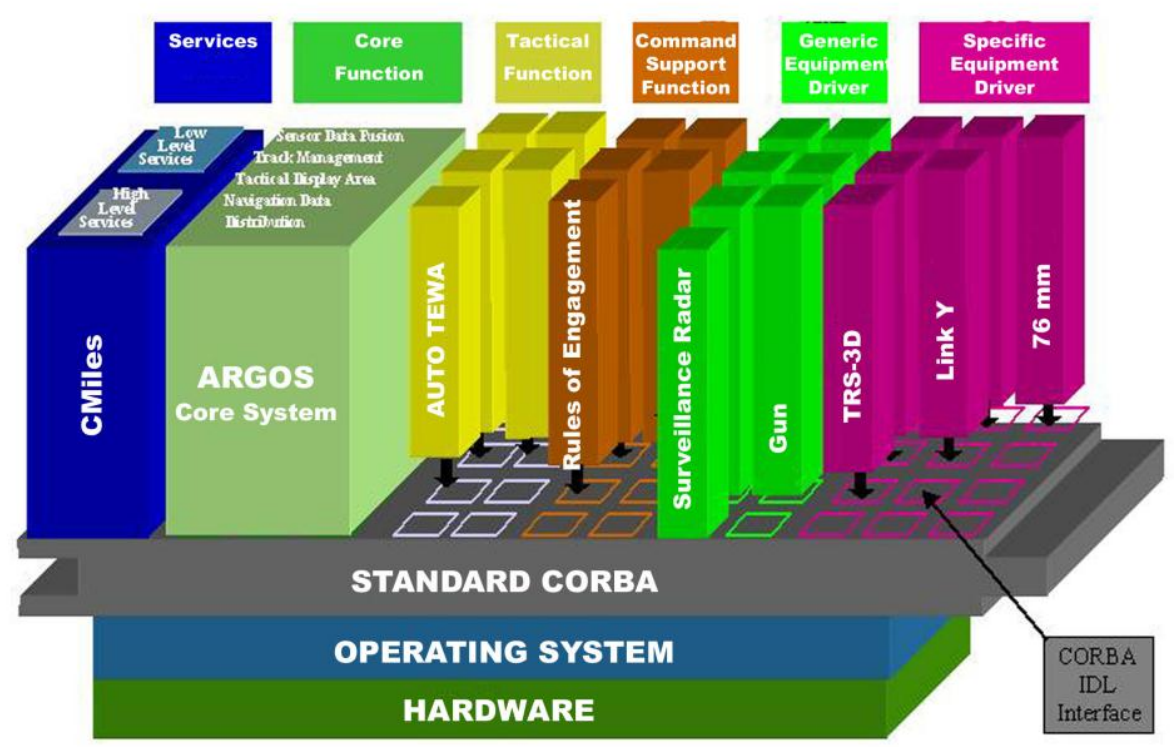

Figure 8: Advanced Combat System Architecture.

\section{Sensors for Littoral Warfare}

The complexity of the littoral environment results in challenging requirements for the performance of the sensor suite (Figure 9). The shoreline configuration with land masses and islands may well restrict the overall radar performance and generate inaccuracy of sensor measurements. Land clutter, numerous false targets, as well as masking of small targets in inshore waters will occur and have an impact on radar performance and the quality of the recognised maritime situation picture.

\section{Underwater Surveillance and Defence}

Naval operations in the demanding conditions of coastal and littoral sea areas may be 


\begin{tabular}{|l|l|l|l|}
\hline Onboard Sensor & Detection Range & Type of Information & Remarks \\
\hline Surveillance Radar & $15-25 \mathrm{~km}$ & $\begin{array}{l}\text { Bearing, Elevation, } \\
\text { Range }\end{array}$ & Multimode 3D Radar \\
\hline IRST & $\begin{array}{l}9-16 \mathrm{~km} \text { (subsonic) } \\
14-27 \mathrm{~km} \text { (supersonic) }\end{array}$ & Bearing, Elevation & $\begin{array}{l}\text { In } 3-5 \mu \mathrm{m} \\
\text { and } 8-12 \mu \mathrm{m} \text { band }\end{array}$ \\
\hline ESM System & $6-10 \mathrm{~km}$ & $\begin{array}{l}\text { Bearing and seeker } \\
\text { parameter }\end{array}$ & $\begin{array}{l}\text { During seeker } \\
\text { operation }\end{array}$ \\
\hline
\end{tabular}

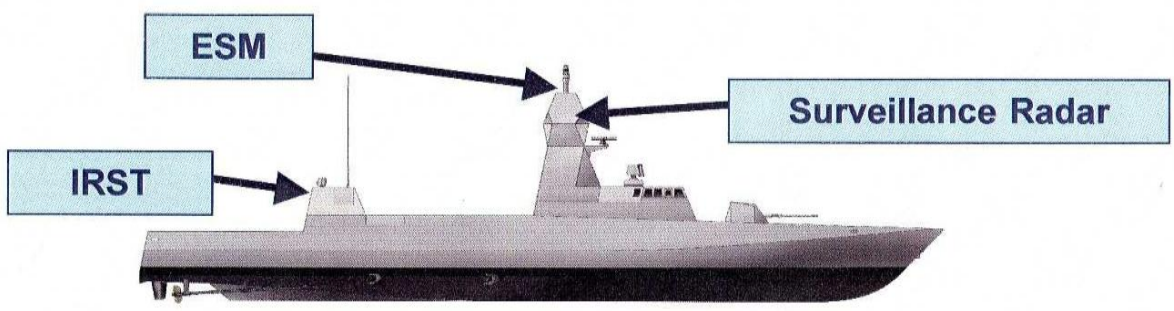

Figure 9: Primary Sensors for Littoral Warfare.

severely threatened or limited by different types of underwater threats which may come from either submarines or defensive sea mines.

In order to ensure survivability and sustainability of vessels employed in littoral warfare, due consideration needs to be given to an adequate underwater defence capability. Depending on the underwater threat of the respective sea area the vessel's underwater defence posture will be based on a multi-sensor sonar system providing the required underwater broad-spectrum surveillance capability, particularly for short detection ranges as typically required in the littoral region. The underwater defence system needs to include and preferably to integrate an effective mine countermeasures (MCM) capability with an anti-submarine/anti-torpedo capability to create a flexible defence system for underwater defence.

\section{Demands for Information Superiority}

Information superiority in the littorals is an important demand for command and control of forces in the littoral environment. Therefore advanced multi-function radars are an urgent requirement to cope with the specific drawbacks in the littoral operational environment. Active phased array radar systems may form the basis for an advanced surveillance sensor in the littoral environment. It provides important features such as rapid automatic detection, classification, tracking of small and fast moving targets including stealthy sea-skimming air and surface targets. Very low false alarm rates and accurate $3 \mathrm{D}$ detection with multi-path elimination at low elevation are fur- 
ther features. The radar's maximum detection range matches the vessel's maximum missile engagement range.

Information superiority requires an effective network of sensors and communications prepared for an adverse electromagnetic environment. In combination, an integrated and fully automated Electronic Warfare (EW) system with ESM for passive electronic surveillance and threat warning remains indispensable for enhanced survivability in littoral operations.

\section{Unmanned Aerial Vehicles}

Unmanned aerial vehicles (UAV) carried on board littoral warfare ships can be employed from corvette-type ships for long range surveillance, reconnaissance, and target identification in a dense environment. Sending targeting information for a long range surface-to-surface missile (SSM) system (third party targeting) can be carried out by UAV without endangering a flight crew of naval helicopters. There are several types of maritime UAV currently under development, which may become operational within a short time period. Due to the relatively small dimensions and weight of UAVs, these airborne drones are a serious and cost-effective solution for an advanced surveillance and intelligence gathering capability needed in littoral warfare vessels in the future.

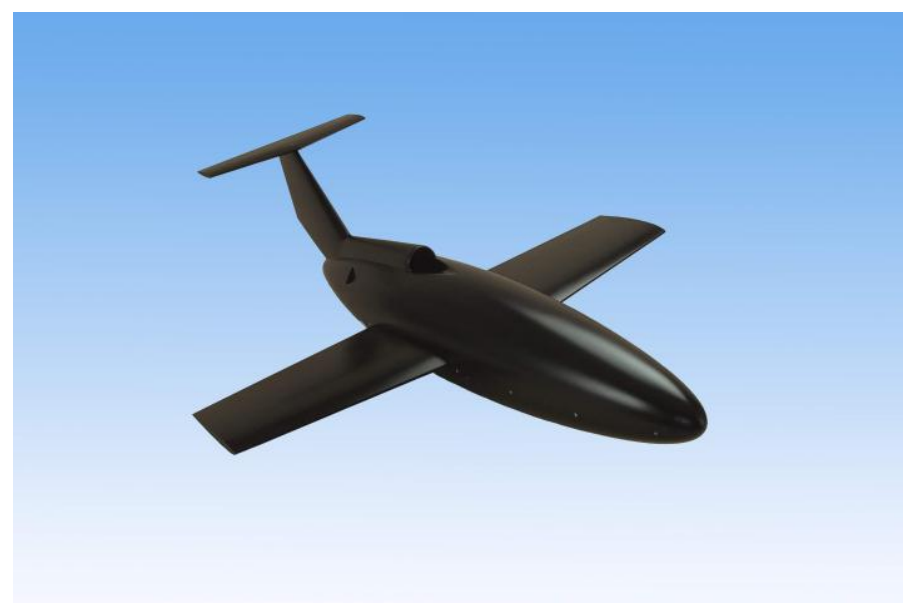

Figure 10: Unmanned Aerial Vehicle (UAV) for Littoral Warfare.

\section{Weapons for Littoral Warfare}

The main wartime missions of littoral warfare ships are Anti-Surface Warfare $(\mathrm{ASuW})$ and the support of operations ashore by Naval Fire Support (NFS). The 
weapon suite on board these vessels is therefore primarily focussed on achieving highest striking power against surface and shore targets at long range. In addition, the weapons on board must clearly ensure optimum self-defence in a multi-threat scenario.

\section{Primary Long Range SSM System}

The primary weapon on board littoral vessels is the long range SSM system which is capable of engaging targets at sea and ashore with a high precision effect. The adequate precision capability of these missiles is required to avoid collateral damage in the target area ashore. For this purpose the missile system is a multi-function system designed for surface target engagements and fitted with a shore target engagement capability ensuring optimum mission effect.

Due to the generally limited size and space on board littoral warfare vessels, the most preferred installation technology for the primary missile system is considered to be the containerised intra-deck (over two to three decks) installation. This method allows for the vertical launch (VL) missile firing mode and provides ample opportunity for enhanced stealth measures at the topside of the vessel.

Moreover, the containerised intra-deck installation method provides a good basis for future upgrades of the missile system for enhanced war-fighting capabilities. The missile containers may well be adapted and utilised for vertical launch of surface-to-air missiles (SAM) for medium range engagements of air targets in an air threat scenario.

\section{Large Calibre Gun System}

For a long range, high precision engagement capability against shore targets a large calibre gun mount capable of firing intelligent, target finding munitions with high mission effect may be an alternative fit.

Since littoral and shallow waters, however, prefer smaller platforms in the range around $100 \mathrm{~m}$ in length, the impact of a large calibre gun mount on weight, space, mobility and also stealth properties of the littoral warfare vessel needs careful consideration and comparison with the advantages of a vertical launch missile system. For larger ships, i.e. frigates, however, this could be a viable solution.

\section{Weapons for $\mathrm{ASuW}$ Role}

Seen from a generic point of view, a standard weapon configuration for the ASuW role will comprise the following components (see Figure 11):

- One long range SSM system as primary weapon with the following features:

- Fitted with shore target engagement capability,

- High precision mission effect ashore, 


\begin{tabular}{|c|c|}
\hline Role \& Employment & Weapon System \\
\hline ASuW & $\begin{array}{l}1 \text { primary long range SSM with land } \\
\text { attack capability } \\
1 \text { medium calibre gun system } \\
2 \text { light calibre guns } \\
\text { growth potential }\end{array}$ \\
\hline AAW / ASMD & $\begin{array}{l}\text { 1 close-in weapon system (PDMS) } \\
\text { alternatively } \\
\text { Combined PDMS and short range } \\
\text { Surface-to-Air Missile system } \\
1 \text { ECM System (Jammer) } \\
\text { Decoy Launchers for chaff / IR }\end{array}$ \\
\hline
\end{tabular}

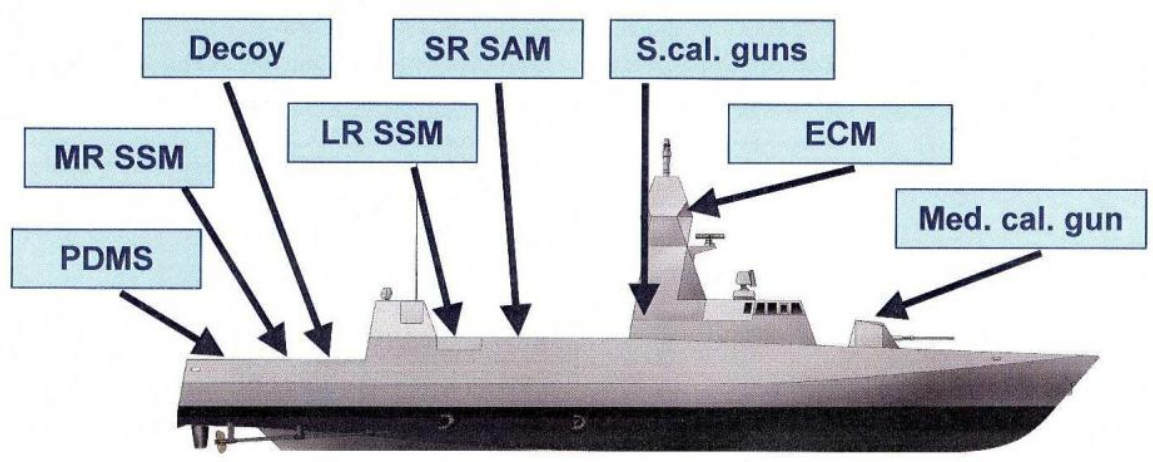

Figure 11: Weapon Suite for Littoral Operations.

○ Vertical launch system (VLS),

- Containerised multi-function munition.

- One medium calibre gun system, especially for surface and shore target engagements at medium ranges. The gun is required for low-key missions such as crisis prevention, embargo control and policing operations. In an air threat scenario the gun will be used for air target engagement and for selfdefence of the vessel. For future ship designs a stealth version of the gun mount is indispensable in order to contribute to the overall requirement for reduced radar signatures and low observability.

- Two or more small calibre guns, with automatic and manual control capability, exercised from the bridge, for immediate reactions and surface target en- 
gagements in case of a sudden attack by high speed boats and/or other forms of asymmetric surface threats.

This weapon configuration covers the full range of possible littoral warfare missions within the ASuW spectrum.

\section{Weapons for Anti-Air Warfare Role}

In littoral warfare operations vessels are exposed to multiple threats from hostile land-, air- and sea-based weaponry. Survivability and mission sustainability are therefore of major importance. With respect to the Anti-Air Warfare (AAW) role of littoral ships the main objective is self-defence or more specific anti-ship missile defence (ASMD).

To ensure an adequate self-defence posture, hard and soft kill weapons are needed on board the littoral warfare vessel:

1. One point defence missile system (PDMS) to engage missiles and other air targets within the vessel's vital close-in zone of about 4 miles around the vessel. Mandatory is a launcher arrangement to ensure missile engagement coverage of a full $360^{\circ}$ azimuth around the vessel.

The PDMS must be fully integrated with the ship's combat management system (CMS) for rapid and automatic reaction. The target designation data is being provided by the ship's passive and active sensors. The missile of fire-and-forget type is guided by passive RF and IR features with the ability for day and night/all-weather operation.

2. Alternatively the PDMS as well as the medium range (MR) surface-to-air missile (SAM) system can be launched from a vertical launching system (VLS).

Mandatory again is an installation arrangement with full $360^{\circ}$ azimuth missile engagement coverage. The MR SAM system which is currently being developed and will be soon operational within the NATO naval weapon inventory enables the littoral warfare vessel to engage missiles and other air targets at an extended range of about twelve miles. The option "Combined PDMS/MR SAM" is logically dependent on the specific operational requirements for the respective vessel. The installation will have an impact on the length of the vessel.

3. The dual-role medium calibre gun mount, which is an essential weapon for the ASuW role as described above, is of course seen also as a valuable means to support the ship's AAW role, in particular for engagement of air 
targets such as rotary aircraft and helicopters at a maximum effective range of about three miles.

Future trends and studies on the gun system concentrate on the development of new ammunition for the anti-ship missile role through the development of a sub-calibre guided projectile with canard control which is fully compatible with the existing loading and firing mechanisms of present gun mounts. The new guided ammunition is designed and intended to defeat sub- and subsonic missiles, sea-skimming and high diving air as well as any other fast manoeuvring target.

\section{Integrated Communications}

Prompt and efficient communication is essential for the sophisticated operational scenarios on modern warships. Today's communications systems for ship-borne applications are designed in accordance with the roles they undertake in times of emergency and in the environment in which they operate. One of the major design objectives is to centralise the activities of integrated communications control and also provide easy access to the communication facilities from various locations.

An Integrated Communications System fulfils the technical requirements for tactical, administrative and safety communication link for a modern naval vessel. The system provides ship-ship, ship-shore, as well as ship-air communication facilities, i.e. military as well as civil communications in all applicable modes of operation. The modes of operation include voice communication (encrypted as well as decrypted), all required RATT modes and data communication, e.g. on LINK 11, LINK 14 and other LINK, according to the special tasks. The frequency range covered is from LF to UHF. The communication can also be laid out to supply voice and data line interfaces for dedicated military SHF-SATCOM equipment. For communication with submarines an underwater telephone may be advisable.

The external communication needs to comply with the international IMO/SOLAS (GMDSS) requirements.

The backbone of a modern integrated communications system is to include:

- Digital communications network,

- Communications management system,

- Secure automatic military messaging system,

- Multifunction integrated antennas, and

- Internal communications system. 


\section{Digital Communications Network}

The digital communications network provides features such as digital audio processing, distributed topology, fibre-optical cables, redundancy and survivability.

\section{Communications Management System}

The overall communications management system includes a number of management terminals which are prepared for control of system and communication network equipment. By a gateway to the combat management system, all functions are partly or fully allocated to multifunction consoles of the CMS.

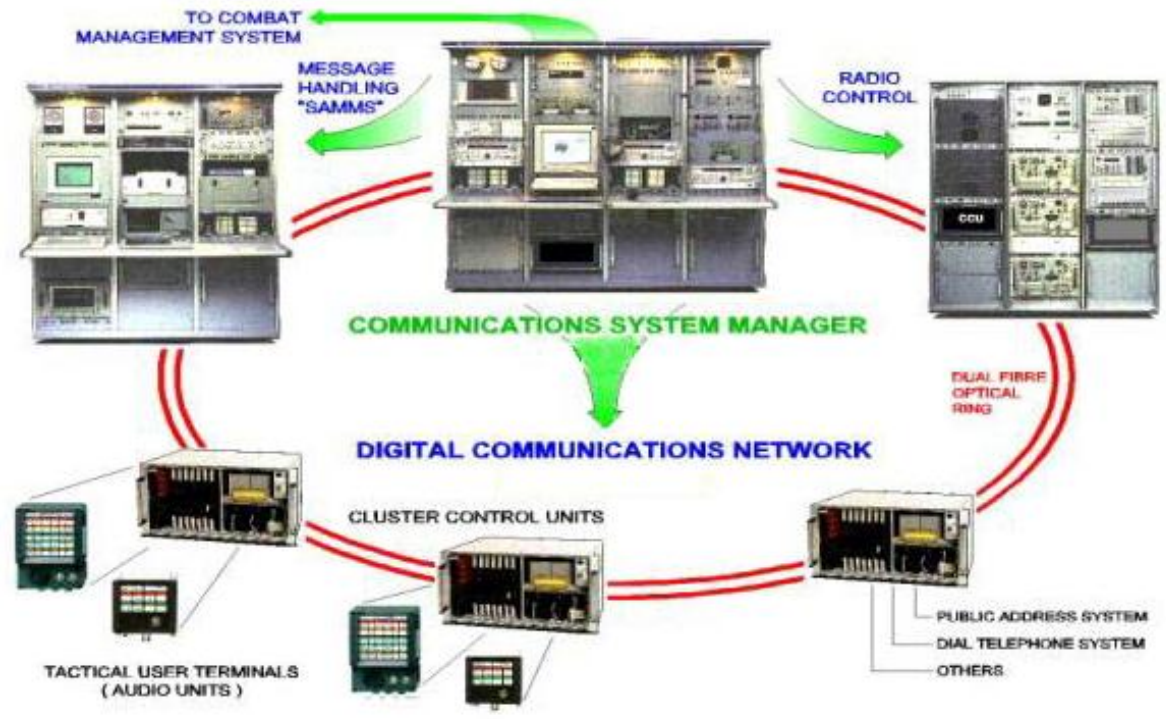

Figure 12: Communications System.

Secure Automatic Military Messaging System

The secure automatic military messaging system provides convenient, menu guided, ACP 127 message handling including automatic routing and distribution of messages.

Integrated Multifunction Antennas

Integrated multifunction antennas are vital components installed on modern warships of stealth technology. The antennas are integrated in the ship's structure or integrated in a multifunction mast module. 


\section{Internal Communications System}

The internal communication consists of different subsystems according to the needs, which are installed at all relevant and redundant positions throughout the vessel. They cover:

- Tactical intercom,

- Public address and alarm system,

- Automatic telephone system,

- Sound-powered telephone system,

- Entertainment system, and

- CCTV.

\section{Conclusion for Future Communications Systems}

Advanced military Communications Systems have to be adaptive to the various mission/roles of the vessel. The increase of information exchange and the lowering of reaction time have to be supported by the Communications System. Ergonomic manmachine interfaces are self-evident requirements. Interoperability with other ship's subsystems is mandatory design objective for modern ship-borne Communications Systems.

\section{Navigation System}

The traditional skills of celestial observations, dead reckoning and harbour piloting, handed down through the centuries, are giving way to integrated computerised navigation systems and electronic charts, referred to as Integrated Bridge Systems (IBS). IBS will automatically collect, process and display ship's navigation and other sensor data in order to maximise bridge watch efficiency and navigational safety. In a modern IBS, data is gathered automatically from the vessel's navigation sensors, navigation radar and other devices. The data is fed directly into a computer, where it is instantly converted into a single integrated picture that shows the ship's position and movement in real time on a colour electronic chart display (ECDIS). IBS and ECDIS provide important tools to enhance the safety of the ship and improve situation awareness. Integrated Bridge Systems comprise the following major modules:

- Planning station,

- Navigation station with ECDIS,

- Conning display,

- Autopilot system and steering control,

- Navigation radar, and

- Navigational sensors, 
which all are tied together by a Local Area Network (LAN), under control of a management software.

The navigation systems are grouped as a compact system in the integrated bridge according to modern, ergonomic design. Workstations in the bridge or in other locations anywhere in the vessel are networked to provide full functionality at any location. In the event of failure of any station, all other stations remain available for operation. In addition to navigational data, supplementary data from the ship's service and from the combat system are available to the watch-keeping officer on the IBS workstations.

\section{Summary}

Current warship design and construction worldwide are undergoing a period of considerable change calling for a wider spectrum of capabilities. Currently, littoral warfare operation is the dominating topic for future naval vessel designs.

Future littoral vessels need to operate across a scope of defence missions ranging from conflict (hot war) through collective, multi-national peacekeeping to defence diplomacy (crisis prevention and management) and to policing tasks, such as countering drugs and piracy. These modern vessels with advanced capabilities are considered to be an amalgam of innovative, highly integrated technologies which partly are and still have to be developed.

LÜRSSEN, the German shipyard for high quality surface vessels since 1875, has analysed and outlined essential features of current and future designs for corvettes and frigate-sized ships which are intended for employment in littoral warfare. Notwithstanding the constantly growing amount of budgetary constraints of most national procurement programmes, LÜRSSEN has in the past and continues for the future to provide viable approaches for advanced technologies to meet the challenging requirements of future littoral combat ships.

For further information please contact: defence@luerssen.de or www.luerssen.de.

Copyright Notice: The use of any picture given within this article is subject to the written permission by Fr. Lürssen Werft GmbH \& Co. KG; Phone: +49 4216604 334; Fax: +49 421 6604 395; E-mail: defence@luerssen.de. 